\title{
La arquitectura en los barrios: puntos de encuentro entre la academia y el saber popular
}

\author{
Architecture in neighborhoods: meeting points between academia and popular \\ knowledge \\ A arquitetura nos bairros: pontos de encontro entre a academia e o saber \\ popular
}

Hernando Carvajalino-Bayona

Universidad Católica de Colombia. Bogotá (Colombia)

Facultad de Diseño, Programa de Arquitectura

Carvajalino-Bayona, H. (2019). La arquitectura en los barrios: puntos de encuentro entre la academia y el saber popular. Revista de Arquitectura (Bogotá), 21(2), II2-125. doi: http://dx.doi.org//0.14718/ RevArq.2019.21.2.2301

\section{(c) (1) (3)}

Arquitecto, Universidad La Gran Colombia.

Magíster en Urbanismo, Universidad Nacional de Colombia. Director de Barrio Taller, entidad que asesora procesos habitacionales populares.

www.barriotaller.org.co

(iD) https://orcid.org/0000-0002-798I-786X

hcbch.barriotaller@gmail.com

\section{Resumen}

Involucrar a la academia en contextos urbanos de periferia, además de aproximar a los estudiantes a problemas reales de nuestras ciudades, permite la estructuración de nuevas propuestas metodológicas participativas, que establezcan relaciones más horizontales entre el saber académico y el popular, alrededor del propósito común de mejorar los barrios populares. En este artículo se presenta la argumentación teórica, la propuesta pedagógica y los resultados alcanzados en el Programa de Arquitectura de la Facultad de Diseño de la Universidad Católica de Colombia (Bogotá), en cuanto a una intervención en asentamientos de periferia. En la introducción se incluye una postura crítica inicial y el desarrollo de algunos conceptos clave que sustentan la propuesta metodológica, su implementación y resultados en una relación estrecha con líderes de la comunidad; finalmente, se proponen una discusión y unas conclusiones acerca de los avances en el estudio de caso, con miras a proyectar este proceso con nuevas dinámicas académicas en estos barrios de origen informal.

Palabras clave: asentamientos humanos; barrios populares; mejoramiento integral de barrios; producción social del hábitat; segregación socioespacial; urbanización informal; vivienda progresiva.

\begin{abstract}
Involving academia in peripheral urban contexts, in addition to bringing students closer to real problems in our cities, also allows for the creation of new participatory methodological proposals that establish more horizontal relationships between academic and popular knowledge, with respect to the common goal of improving working-class neighborhoods. This article presents the theoretical arguments, pedagogical proposal, and the results obtained in the Architecture Program of the Design School of the Catholic University of Colombia (Bogota) with respect to an intervention in peripheral settlements. The introduction includes an initial critical posture and the development of some key concepts that support the methodological proposal, its implementation, and results in a close relationship with community leaders. Finally, the article proposes a discussion and some conclusions regarding the progress of the case study, with the aim of projecting this process with new academic dynamics in these informal neighborhoods.
\end{abstract}

Keywords: Human settlements; working-class neighborhoods; comprehensive improvement of neighborhoods; social production of habitat; socio-spatial segregation; informal urbanization; progressive housing.

\section{Resumo}

Envolver a academia em contextos urbanos de periferia, além de aproximar os estudantes de problemas reais de nossas cidades, permite estruturar novas propostas metodológicas participativas que estabeleçam relações mais horizontais entre o saber acadêmico e o popular, ao redor do objetivo comum de melhorar os bairros populares. Neste artigo, apresentam-se a argumentação teórica, a proposta pedagógica e os resultados atingidos no Programa de Arquitetura da Faculdade de Desenho da Universidad Católica de Colombia (Bogotá), no que se refere a uma intervenção em assentamentos de periferia. Na introdução, expõem-se um posicionamento crítico inicial e o desenvolvimento de alguns conceitos-chave que apoiam a proposta metodológica, sua implantação e resultados em uma relação estreita com líderes da comunidade; finalmente, propõem-se uma discussão e umas conclusões sobre os avanços no estudo de caso, com vistas a projetar esse processo com novas dinâmicas acadêmicas nesses bairros de origem informal.

Palavras-chave: assentamentos humanos; bairros populares; melhora integral de bairros; produção social do hábitat; segregação socioespacial; urbanização informal; moradia progressiva. 


\section{Introducción}

En América Latina, la mayor parte de la población económicamente más pobre acude a la urbanización de origen informal para procurarse un cobijo, una vivienda. Nuestro país no es la excepción, pues mediante procesos colectivos e individuales buena parte de estas familias construye de manera progresiva los barrios populares, caracterizados por sus precarias condiciones urbanas y habitacionales, precariedad que va desde su localización en las periferias urbanas -incluidas algunas en zonas de riesgo por inundación o por remoción en masa, las cuales ponen en peligro la vida de sus habitantes-, hasta la deficitaria construcción de sus viviendas, en las que se presentan problemas de vulnerabilidad sísmica en lo estructural, y de habitabilidad en la configuración espacial (Figuras 2 y 3 ).

Sin embargo, al ir más a fondo en estos territorios, de forma simultánea encontramos otras variables y conceptos, propios del lugar y de los pobladores, que se han venido construyendo en el tiempo, a través de la urgencia y de la lucha por un techo. Entre otros, desde lo colectivo podemos destacar el concepto de solidaridad y autoproducción de sus viviendas, la evidente progresividad, lo diverso y lo heterogéneo en la idea de vivienda concebida por las familias, acompañadas de su maestro de obra a quien contratan para la construcción, y la vivienda productiva como fuente de ingresos para el sustento económico que puede brindar una tienda, un taller o el arriendo de espacios a algún inquilino; también se encuentra el refugio para la familia extendida que va creciendo con el tiempo. Por etapas, o como decía coloquialmente alguna vez un poblador, "paso a paso, peso a peso y piso a piso" (Carvajalino, 2016, p. 62), se va consolidando la vivienda, como también lo planteó John Turner (1977) hace varias décadas, en su libro La vivienda, todo el poder para el usuario.

Asimismo, se puede evidenciar el papel de la calle como espacio público de encuentro por excelencia y las manifestaciones estéticas en las viviendas propias del lugar que le sirven como marco a nivel de los perfiles urbanos de la cuadra, las cuales forman parte de la expresión de la cultura popular propia de estos barrios. El "engalle" de las viviendas le da una particularidad a sus fachadas, mediante una ornamentación en la que se hace relevante la diversidad en el color, que contrasta con el gris y el terracota de los muros sin pañetar (Figuras 4 y 5).

Para el arquitecto Fabio H. Avendaño (2003, p. 418), el "barrio en su totalidad materializa lo que se está renovando, lo que se está construyendo, lo que nunca se concluye, lo que colma una inmediatez, sin compromiso con lo definitivo", lo que obliga a que en este tipo de estudios este proceso continuo de construir sobre lo construido forme parte de las evidencias que vamos encontrando en nuestras visitas de campo: las de un barrio en

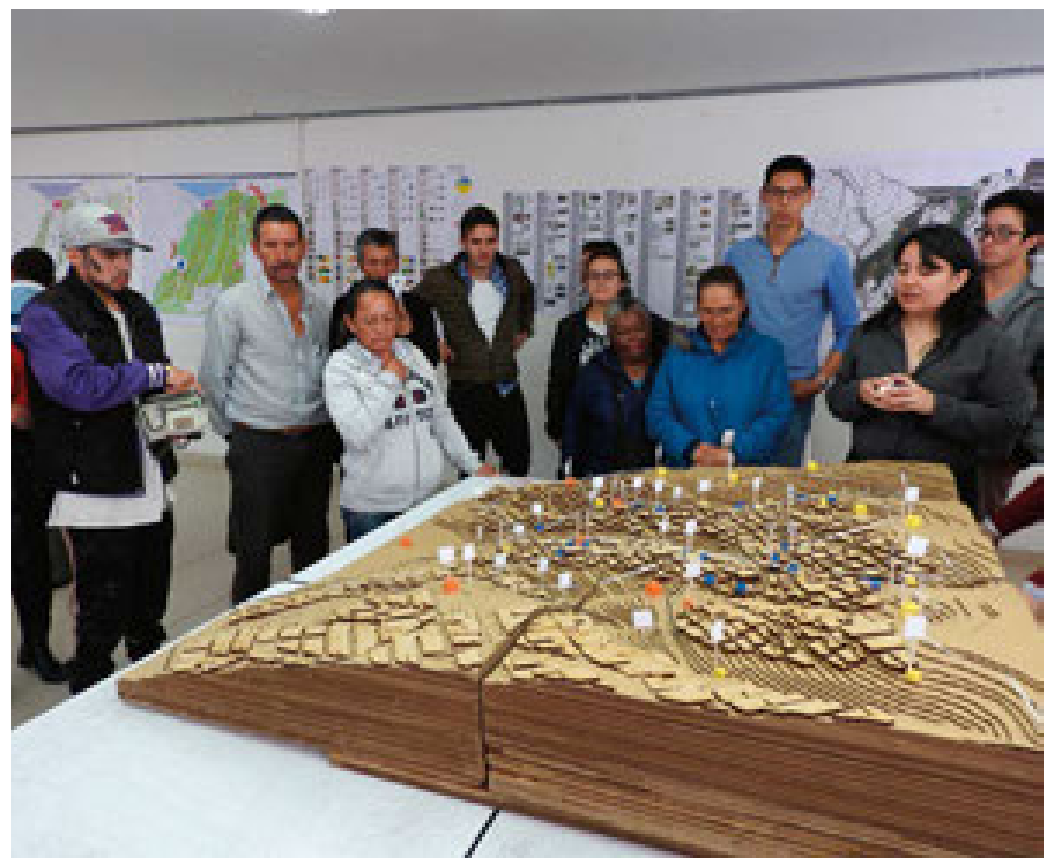

(A) Figura 1. Los estudiantes exponen avances del proyecto a los pobladores

Fuente: Hernando Carvajalino Bayona, 2017.
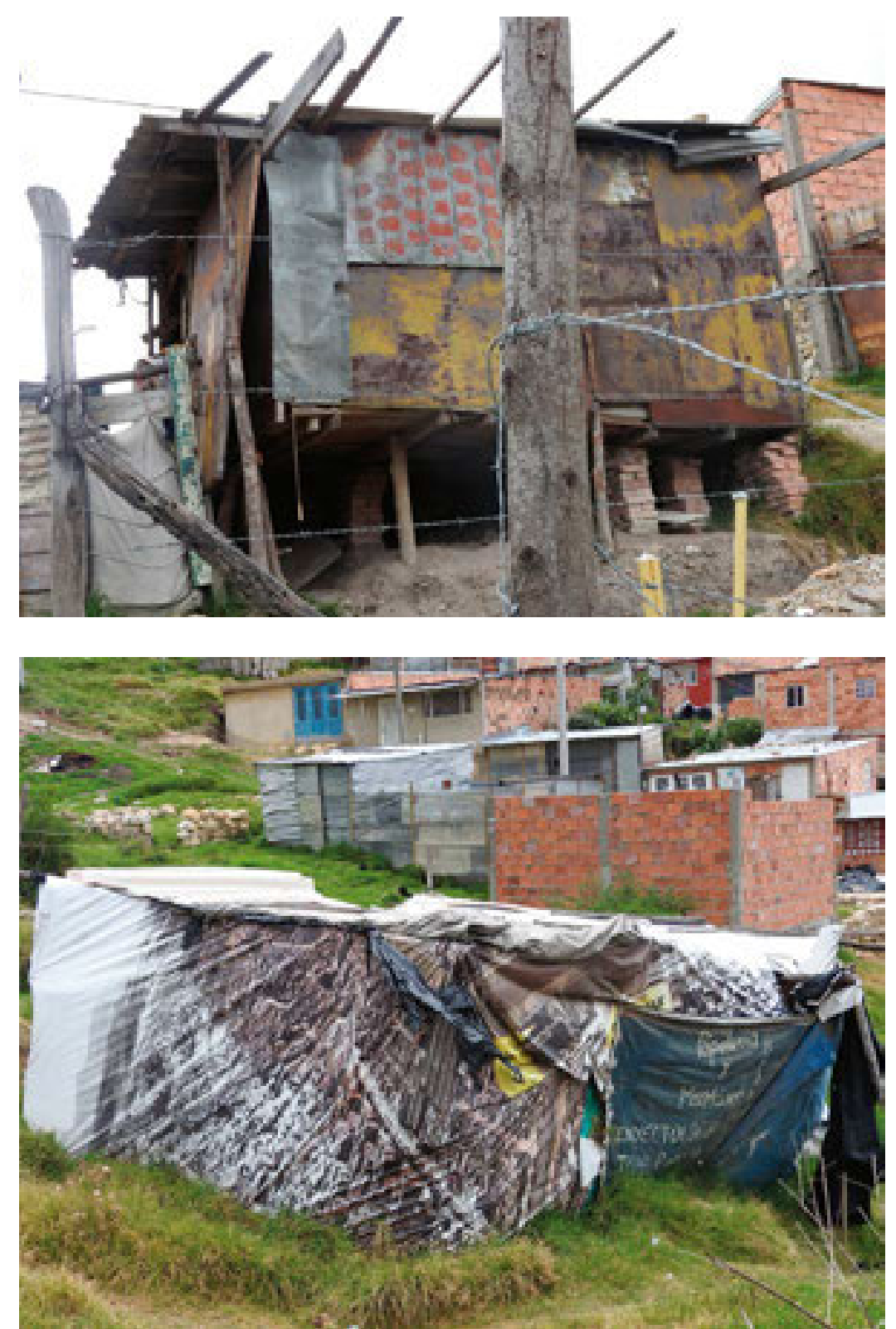

(A) Figura 2 y 3 . Viviendas (A) provisionales, ranchos o tugurios Fuente: Hernando Carvajalino Bayona, 2017. 


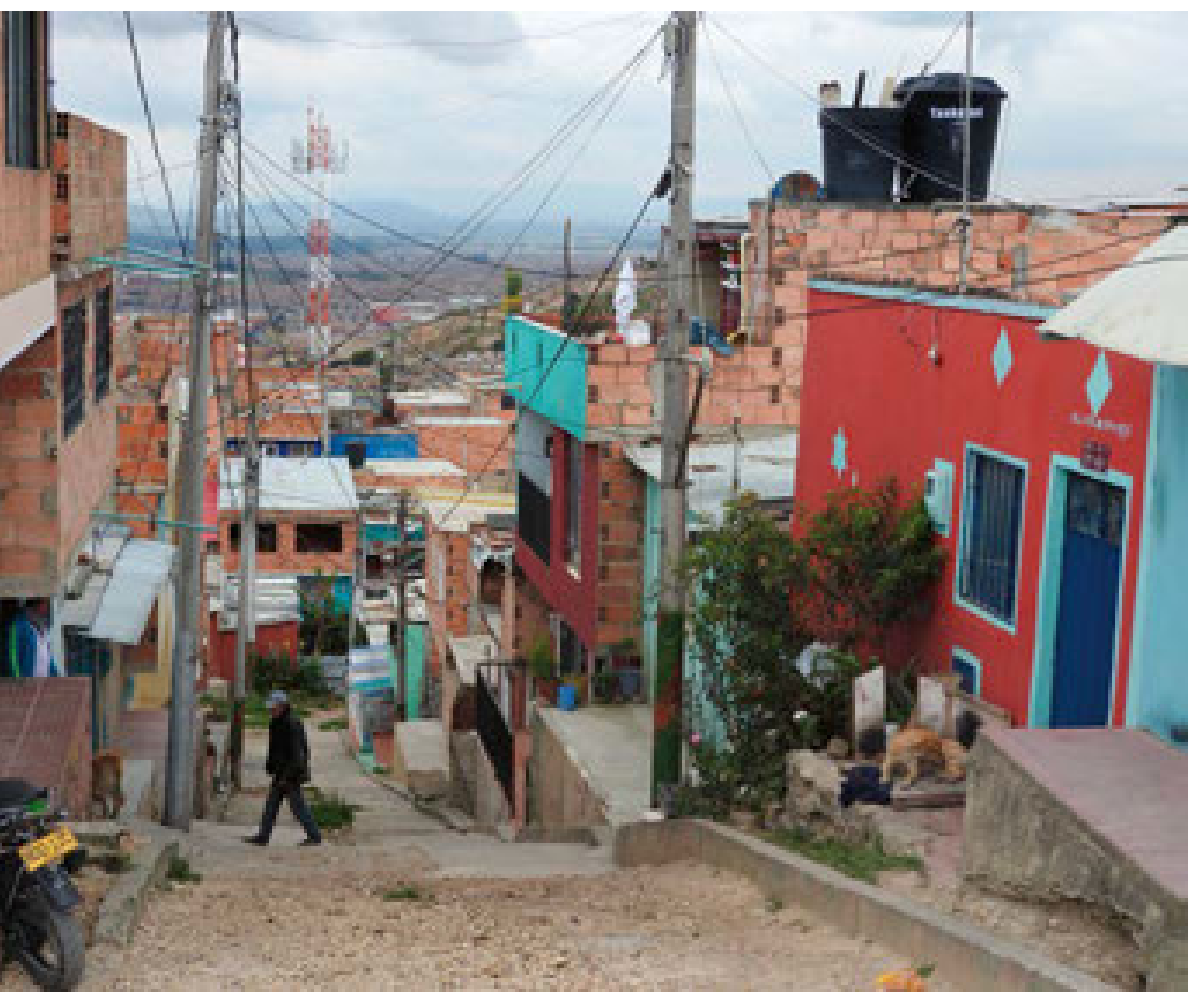

(A) A Figuras 4 y 5 . Calles y viviendas del barrio

Fuente: Hernando Carvajalino Bayona, 2017. continuo crecimiento. En estos asentamientos, continúa el arquitecto, "no hay una identidad colectiva, en cuanto a algo constante y unificador. Por el contrario, dentro de estos contextos lo diverso es lo común, el desarrollo de lo inconcluso configura una serie de pausas individuales, de manifestaciones del esfuerzo de quien pretende solventar un problema individual" (p. 418). Este escenario complejo y dinámico es el que se aborda por parte de estudiantes y profesores en cuanto a su estudio y reflexión, y a la acometida de sus problemáticas, con la consecuente proposición a nivel de proyecto.

Sin embargo, desde la vida academia, en particular desde las facultades de Arquitectura, la distancia que se ha establecido hacia estos asentamientos ha sido muy grande. Si bien en los últimos años se han generado espacios académicos estables y con permanencia en el tiempo en algunas universidades, no son estos los casos más comunes, pues la arquitectura tradicional -que permite una mayor elucubración formal para estratos económicos más elevados- es la que tiene más presencia en nuestras facultades. De allí que estos territorios en los que se plantea la necesidad de mejorar lo construido como prioridad por atender, en medio de tantas limitaciones, no sean muy solicitados para el desarrollo de trabajos de final de carrera.

Por esta razón habrá que seguir consolidando un cuerpo conceptual fuerte y una práctica coherente, frente a la crítica que todavía se escucha en los pasillos acerca de que en este tipo de experiencias es más lo que se "juega al sociólogo" (Carvajalino, 2016, p. 57), que lo que se "hace de arquitectura", etiquetándola casi siempre de manera despectiva como "arquitectura social". Sistematizar y escriturar estos procesos formará parte, en adelante, de esta construcción argumental que sustente nuestra práctica cotidiana en los barrios, en el taller y en el salón de clase.

Al respecto, en el Programa de Arquitectura de la Facultad de Diseño de la Universidad Católica de Colombia se ha abierto un espacio importante, desde el cual se aborda este tipo de escenarios, con el propósito cada vez más evidente de aproximar la academia a la realidad social de la ciudad y del país. Si bien de tiempo atrás se venían haciendo ejercicios académicos que de manera tangencial abordaban la problemática habitacional de estos barrios, es en el año 2011 cuando se adelanta una primera experiencia piloto a fondo, en la que se compromete un volumen grande de estudiantes y docentes en el Proyecto La Paz Sector Naranjos en Bogotá, en convenio con entidades distritales, a la cual se hará referencia en páginas posteriores.

En un principio, un aspecto importante por destacar es el abordaje del problema, que el estudiante desarrolla a partir de preguntas clave que le permitan profundizar en el tema, inicialmente a una escala barrial, $y$, posteriormente, a nivel del proyecto arquitectónico puntual. Estas preguntas estarán vinculadas, no solo a una búsqueda preliminar desde la revisión bibliográfica y la consecuente reflexión, sino también estarán muy ligadas a la lectura del lugar y a los recorridos e intercambios con los habitantes del barrio; ese cruce fundamental con lo cotidiano y lo vivencial que va más allá de lo puramente físico y territorial. Asimismo, se propone avanzar en un vínculo más estrecho de integralidad entre el diagnóstico (expediente urbano) y el diseño, al igual que entre el discurso (argumentación) y la planimetría del proyecto, como también en el diálogo de saberes que se quiere establecer con los pobladores y la respuesta urbano-arquitectónica, buscando que esa coherencia se haga presente de forma transversal entre la fase inicial de acercamiento al problema y al territorio, y las fases siguientes de diagnóstico, planeación y diseño, en las que el componente consultivo y participativo con la 

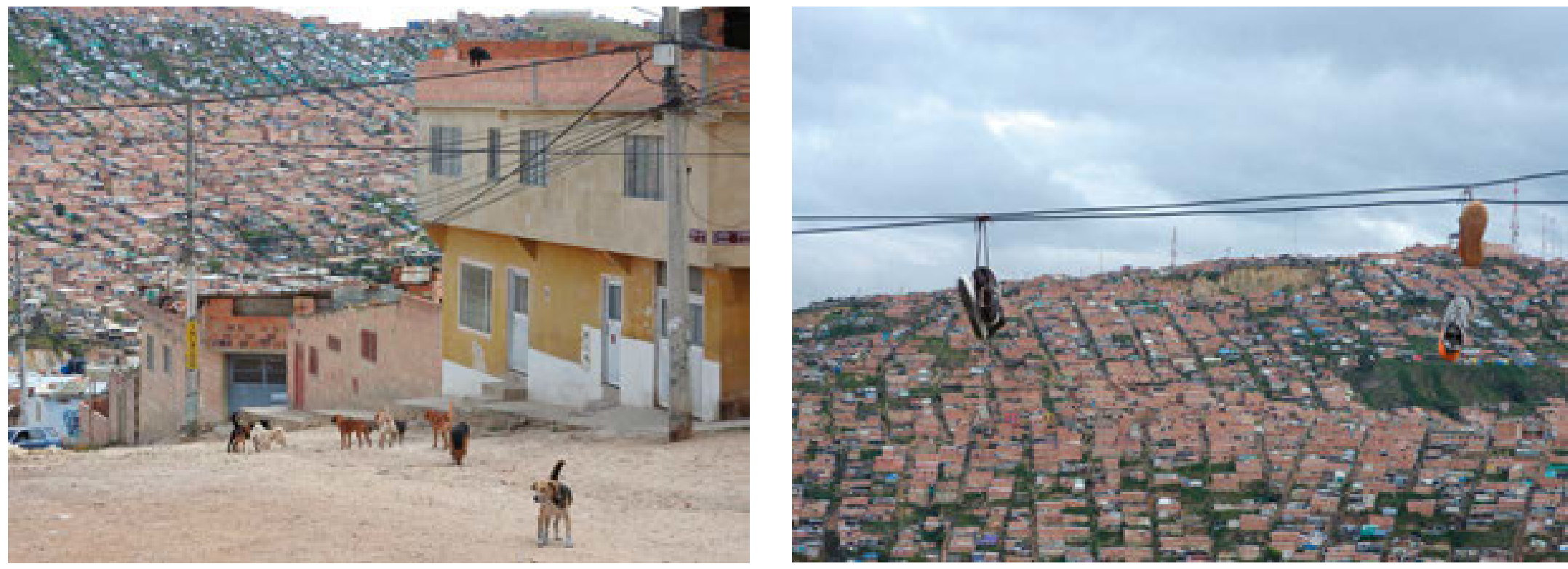

comunidad debe ganar un protagonismo cada vez más crucial.

Como innovación dentro del ejercicio académico, la propuesta de diseño concurrente, que integra alrededor de un mismo proyecto las cátedras correspondientes al Diseño Urbano, Arquitectónico y Constructivo como método de trabajo propio en la facultad, es el núcleo central en el que se fundamentan estos alcances de integralidad y de coherencia en las distintas escalas que se proponen en este tipo de proyectos; su sintonía conceptual y el cuerpo metodológico común del trabajo práctico nos permite que, como grupo de profesores, nos relacionemos y nos integremos alrededor de un mismo propósito, en el acompañamiento que se le hace al grupo de estudiantes, mediante un programa común y espacios abiertos en los que nos encontramos periódicamente en una misma clase.

\section{Metodología}

Este trabajo académico en los barrios de Ciudadela Sucre de Soacha, desarrollado a partir del año 2013, tiene un antecedente importante referido al ejercicio teórico-práctico que se desarrolló en los dos años que le antecedieron, con la activa participación de la Secretaría Distrital del Hábitat y de la Caja de la Vivienda Popular, en el barrio La Paz Sector Naranjos ${ }^{1}$, de la localidad Rafael Uribe de Bogotá. A partir de los logros alcanzados en esta experiencia, centrada en la formulación de planteamientos urbanos para el sector y en propuestas de mejoramiento de vivienda y de redensificación, la ONG internacional Hábitat para la Humanidad, con una vasta trayectoria en el campo de lo habitacional, a comienzos de 2013 contacta a la Facultad de Diseño, Programa de Arquitectura, para adelantar una experiencia conjunta en sectores popu-

1 Parte de esta experiencia inicial se encuentra reseñada en e artículo "Aprendiendo del barrio La Paz. Un escenario desde el cual vincular la academia a esta otra arquitectura" (Carvajalino, 2013, pp. 120-130). lares donde ellos venían trabajando desde hacía un par de años, barrios habitados por familias de bajos recursos, que formaban parte de la misión de esta organización. A partir de conversaciones entre las directivas de ambas instituciones, se llega a un acuerdo para que estudiantes de la facultad, adelanten su trabajo de grado de IX y X semestre en barrios de Ciudadela Sucre.

Los barrios que conforman la Ciudadela Sucre son lugares con una alta vulnerabilidad social, que se localizan en límites con la localidad de Ciudad Bolívar, de Bogotá, muy cerca de barrios como Caracolí, Potosí y Arborizadora Alta. Sitios que tradicionalmente han sido receptores de población desplazada por el conflicto armado y social que durante décadas ha vivido el país ${ }^{2}$. Se trata, entonces, de un territorio urbano conformado por diez barrios populares de origen informal, ubicados en la Comuna 4 de Soacha, cuya fundación data de hace más de 35 años, proceso que fue liderado en su momento por Rafael Forero Fetecua, reconocido urbanizador informal de aquellos años. Barrios en proceso de consolidación, con problemas evidentes en cuanto a ausencia de oportunidades laborales y económicas, conflictos sociales diversos y precarias condiciones habitacionales, tanto en lo urbano (lo público y lo colectivo), como en lo habitacional (la vivienda). No obstante, al ahondar en estos escenarios es posible evidenciar de forma paralela oportunidades, en lo colectivo y lo individual, y un potencial que se puede aprovechar para el mejoramiento del barrio, con el acompañamiento de agentes externos que pueden aportar a las dinámicas comunitarias propias de estos asentamientos en proceso de consolidación (Figuras 6 y 7).

\footnotetext{
2 Un primer avance de esta experiencia se presentó en el Seminario Internacional "Experiencias significativas de recomposición social y urbana", organizado por la Universidad Piloto de Colombia en Bogotá D. C. en octubre de 2015, a través del documento "Programas de mejoramiento barrial. Escenarios comunitarios para aproximar la academia a los barrios populares", del cual se retoman algunos apartes en el presente artículo.
}

(A) (A) Figuras 6 y 7 .

Panorámicas del barrio, al fondo Ciudad Bolívar (Bogotá, D. C.)

Fuente: Hernando Carvajalino Bayona, 2017. 
A nivel de los objetivos del proyecto se plantean los siguientes:

- Aproximar la academia al barrio popular, a través de ejercicios de diagnóstico (expediente urbano) y diseño, que conlleven la estructuración de programas de mejoramiento barrial a escala urbana y el desarrollo de proyectos arquitectónicos puntuales, desde lo público, lo colectivo y lo habitacional.

- Diseñar nuevas propuestas metodológicas desde la academia, encaminadas a desarrollar un trabajo conjunto con los pobladores y sus organizaciones, mediante ejercicios de consulta y de participación comunitaria.

- Vincular la universidad al trabajo comunitario que desarrollan distintas instituciones en estos escenarios barriales (ONG, entidades gubernamentales y organizaciones de base).

- Sistematizar la experiencia y consignarla por escrito, como ejercicio que permita profundizar en su reflexión, y en un posible intercambio, en diversos espacios académicos locales e internacionales.

Con el acumulado que se lleva a la fecha, esta experiencia, que ya tiene seis años de trabajo, ha recorrido secuencialmente los siguientes barrios, entre el 2013 y el 2017: Bellavista Alta, Rincón del Lago, Bellavista Baja, Buenos Aires, Villanueva y Las Margaritas, barrios vecinos entre sí. Con un ejercicio a más largo plazo se tiene la perspectiva de ampliar este trabajo a los demás barrios de Ciudadela Sucre, en los que se ha trabajado en conjunto con Hábitat para la Humanidad, la Orden Hospitalaria San Juan de Dios, $y$, mancomunadamente, con las directivas de las juntas de acción comunal de los barrios, como también con diversos líderes comunitarios y con

(1) (1) Figuras 8 y 9. Recorrido por el barrio y reunión con la Junta de Acción Comunal Fuente: Hernando Carvajalino Bayona, 2016

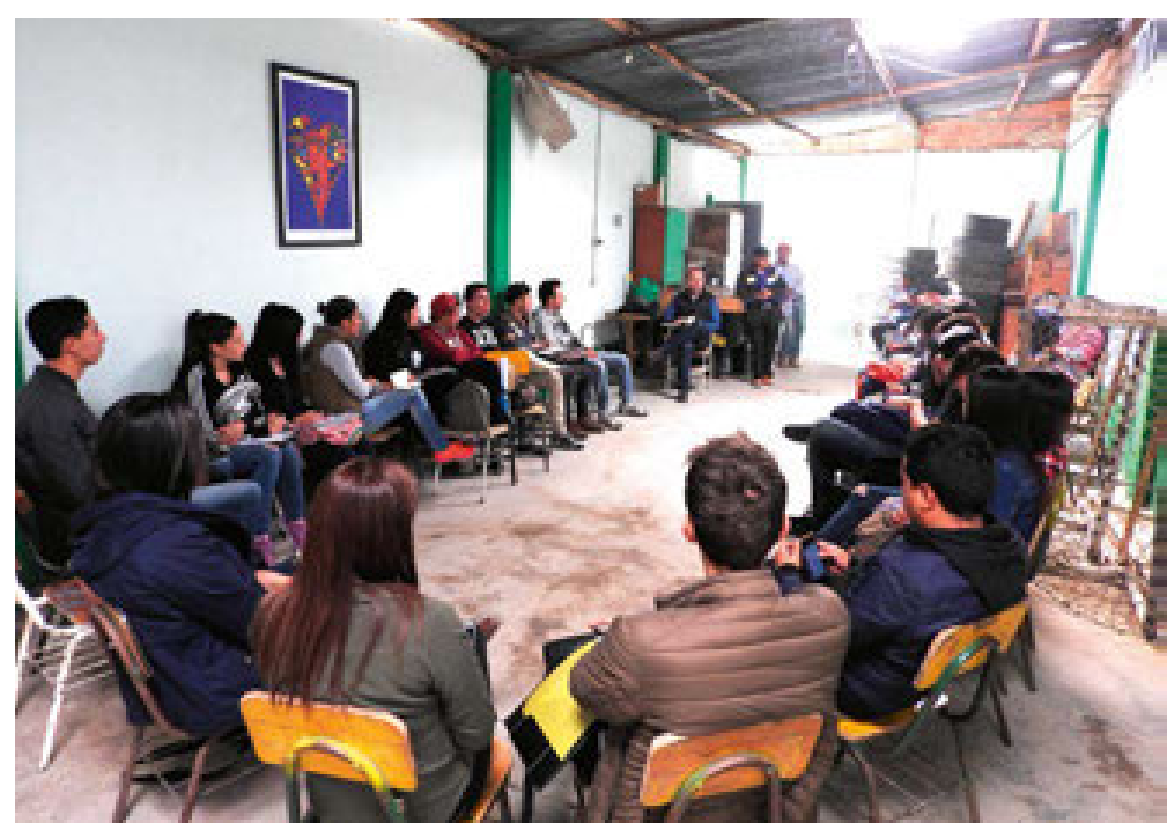

tigación formal dentro de la universidad, ni tampoco de extensión universitaria. Se ha desarrollado, más bien, desde el espacio limitado que brinda la hora cátedra, y, en tal sentido, corresponde al trabajo que se adelanta por parte de tres áreas de estudio (Diseño Urbano, Arquitectónico y Constructivo) que de manera conjunta y coordinada trabajan integralmente en función de este proyecto, tanto en su parte teórica como en su parte proyectual y práctica, con estudiantes de IX y X semestre, que a lo largo de un año desarrollan su trabajo de grado en estos escenarios. A la fecha han sido seis grupos de estudiantes, uno por año, cada uno con promedio de quince, los que han dedicado esa etapa final de su carrera a estudiar estos barrios y a proponer sus proyectos tanto urbanos como arquitectónicos, teniendo en cuenta las necesidades y oportunidades encontradas en el territorio, cruzadas transversalmente con el encuentro periódico con los pobladores del barrio en ese intento por estrechar ese diálogo de saberes, el académico y el popular.

A continuación, se mencionan las cinco fases en las que se divide el proceso, las cuales no son necesariamente lineales, pues se traslapan y se cruzan entre sí a lo largo de este proceso que se ha venido estructurando, mediante una construcción colectiva, en torno a una metodología que nos aproxime al barrio popular y a sus habitantes, y a una apuesta por mejorar lo construido, en la que la arquitectura se compromete con estudiar posibilidades para mejorar el hábitat en el que se actúa, en correspondencia con los pobladores que habitan el lugar, de manera consultiva inicialmente y participativa con posterioridad, con el respeto por el lugar y su cultura, y de la mano con las organizaciones que se vinculan a estos otros escenarios de origen informal. Las cinco fases del proceso metodológico son:

- Aproximación conceptual inicial: una lectura desde el aula.

- Recorridos por el territorio, con los pobladores: una lectura paralela desde los barrios.

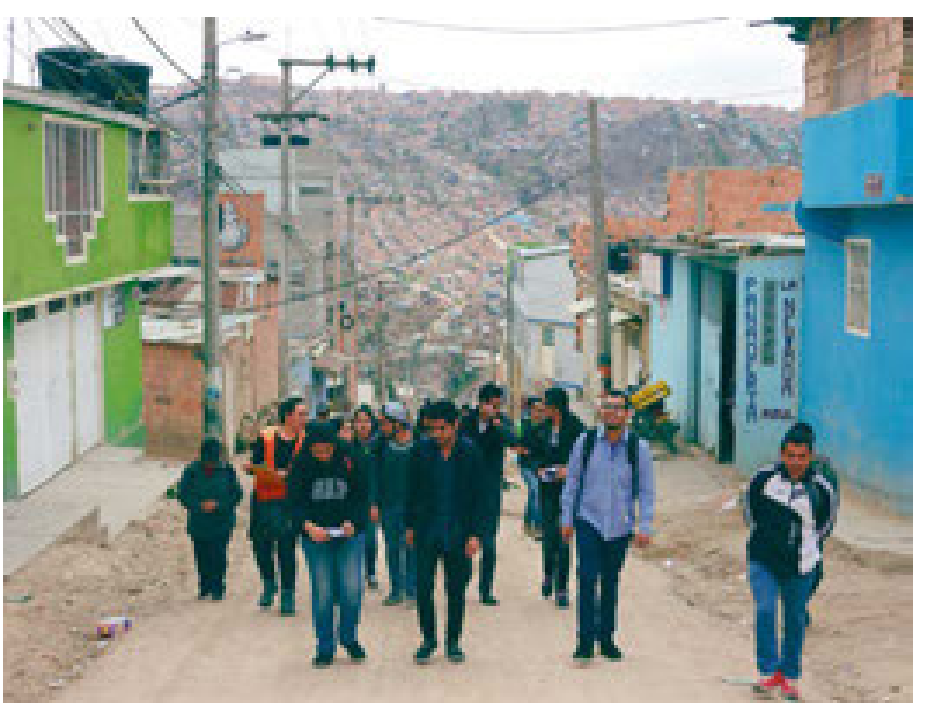


- Expediente urbano (diagnóstico): una primera escrituración sobre el problema y la oportunidad.

- Proposición global: armar el rompecabezas del mejoramiento barrial, desde sus distintas escalas.

- Diseño arquitectónico puntual: desarrollar las piezas del rompecabezas a partir de la estructuración de las ideas proyecto.

\section{Resultados}

A continuación se presenta el desarrollo en profundidad de cada una de estas fases del proceso metodológico, a partir del trabajo teórico-práctico que se adelantó en cada semestre, con el grupo de estudiantes y con las organizaciones con las que se trabaja en cada uno de los barrios.

\section{Aproximación conceptual inicial, una lectura desde el aula}

Una vez expuesto al grupo de estudiantes el planteamiento del trabajo por desarrollar, el cual se adelanta en las clases iniciales, el primer avance del proceso se hará en relación con la revisión y exposición del material bibliográfico base que entregan los profesores, más los textos que consiguen los estudiantes, para comenzar las lecturas y a través de un espacio de seminario teórico, dar inicio a las conversaciones y discusiones sobre el tema de estudio, que llevará a cada estudiante a ir escribiendo sus propios textos y reflexiones. Asimismo, se hace una revisión de trabajos de semestres anteriores, para tener como referencia los estudios de otros compañeros en barrios vecinos.

Esta primera parte se desarrolla al comenzar el IX semestre, a manera de introducción al trabajo complejo que recién se inicia. En este, durante varias semanas se abordan las diversas lecturas relacionadas con el campo del hábitat popular y del mejoramiento de barrios como campo de reflexión inicial en torno a los escenarios en los que trabajaremos a lo largo del año, como posibilidad nueva para la estructuración y el desarrollo del trabajo de grado.

Si bien es una labor que se debe continuar a lo largo de todo el año de trabajo, esta fase inicial es muy importante, pues se pretende encontrar conceptos clave que nos permitan aproximarnos al barrio, con un conocimiento previo desde la bibliografía. A partir de la formulación de preguntas problémicas y de material bibliográfico nos acercamos a un primer escenario teórico del hábitat popular, estructurando de forma paralela una propuesta metodológica que nos aproxime al lugar de trabajo, a su estudio, comprensión y diagnóstico, para formular posteriormente un plan de mejoramiento barrial y su concreción proyectual a través de la formulación de proyec- tos arquitectónicos puntuales, desde el diseño concurrente propuesto por la Facultad (diseño urbano, arquitectónico y constructivo) en su proyecto educativo, basado en la "integración y sincronización de información proveniente de los diferentes campos de acción disciplinar e interdisciplinar" (Facultad de Arquitectura, 2010, p. 12), y del análisis de referentes (ingeniería inversa - dossier), entendido como "proceso de análisis y evaluación tendiente a localizar conceptos significativos presentes en una edificación referente" (p. 23), entre otros, como escenarios académicos que nos brindan los conceptos y las herramientas mínimas para adentrarnos en estos asentamientos.

Las temáticas relacionadas con la problemática habitacional; con las políticas de vivienda vigentes; con los barrios populares, su historia y su morfología; la participación de los pobladores en procesos de diseño, más la vivienda y su espacialidad, serán puntos de encuentro en cada clase. Asimismo, las experiencias locales y de otros contextos a nivel de referentes (dossier), en relación con el mejoramiento de barrios y de vivienda, entre otros temas, los que nos permitirán este acercamiento al conocimiento teórico preliminar, antes de avanzar en el trabajo de campo y en la visita a los barrios.

Como se planteó, este propósito de lectura, análisis y reflexión colectiva será un espacio que se mantiene vivo a lo largo de los dos semestres, con temáticas relacionadas con la coyuntura que se esté tratando en cada momento. El proceso de escritura de estas ideas será un propósito de cada estudiante, el cual entregará periódicamente a través de textos cortos que irá compilando para la elaboración de un artículo final que entregará con su trabajo de grado, con la posibilidad de que este sea publicado a partir de los parámetros editoriales que propone la Revista de Arquitectura (Bogotá) de la Facultad ${ }^{3}$.

Ya uno de estos artículos elaborados por los estudiantes fue publicado. Mildred Laiton (2017, pp. $70-85)^{4}$, en su texto, hace una interesante reflexión argumentativa en torno a la vivienda flexible y presenta su proyecto de grado, localizado en el barrio Buenos Aires de Ciudadela Sucre, en el que combina el potencial de mejorar lo construido y el de habilitar vivienda nueva en una de estas manzanas en proceso de consolidación.

\footnotetext{
3 La Revista de Arquitectura (Bogotá), de la Universidad Católica de Colombia, es una publicación de acceso abierto, arbitrada e indexada, editada por la Facultad de Diseño y el Centro de Investigaciones CIFAR, desde 1999 hasta la fecha.

4 El proyecto de Mildred Paola Laiton, estudiante que participó en este proyecto en el año 2016, fue seleccionado por la Facultad para participar en la Anual de Estudiantes de Arquitectura organizada por la Sociedad Colombiana de Arquitectos, y su artículo de trabajo de grado fue publicado en la Revista de Arquitectura (Bogotá) en el volumen 19 (1) (2017).
} 


\section{Recorriendo el territorio, una lectura paralela desde los barrios}

Si bien se viene reflexionando en torno a la problemática de estudio y al territorio en el que vamos a trabajar, con guías de trabajo establecidas previamente, nos aproximamos al territorio a través de visitas de campo guiadas con el objeto tomar información en el terreno, para luego profundizar en su análisis desde lo urbano, lo arquitectónico y lo social. Esto se hace con el acompañamiento de la Junta Comunal del barrio, y algunos líderes y pobladores del lugar. A través de diversos recorridos y en conversaciones con los pobladores a través de reuniones y talleres de cartografía social, se comienzan a entender las dinámicas propias del barrio y sus lógicas de habitar, tanto en la comprensión de la espacialidad interior de las viviendas y su relación con la estructura ecológica, como también, con el uso del espacio público, de sus calles, esquinas y las manifestaciones estéticas de sus fachadas, entre otras, en un territorio concebido y construido colectivamente (Figura 10). Estos asentamientos, en palabras del arquitecto Walter López (2003, p. 30), "si bien presentan un proceso espontáneo y no planificado se ha podido comprobar qué tanto en sus soluciones urbanas, como en sus resultados arquitectónicos, es posible establecer una serie de patrones y de manejos que dan cuenta de la existencia de lo común en lo diverso". Caminar y recorrer sus empinadas calles será parte de este propósito a lo largo de cada periodo académico; charlar con sus habitantes y escuchar sus historias y necesidades será un propósito permanente que requiere superar en el camino el miedo inicial a lo desconocido y a las etiquetas de inseguridad que desde los medios de comunicación se asignan a estos lugares.
(1) Figura 10. Llegada al salón comunal del barrio

Fuente: Hernando Carvajalino Bayona, 2017.
"Para transformar la ciudad hay que conocerla. Las ciudades se conocen con los pies", planteaban Borja y Castells (1999, p. 265), a lo cual le agregaban: "Hay que pisar en algún momento cada barrio y cada obra y entrar en las casas y hablar con la gente. Transformar la ciudad, supone un estilo de vida" ${ }^{5}$. Este es parte del objetivo que se tiene desde un principio, aproximarse a esa realidad de inmediato y directamente, de la mano de sus pobladores, apuntándole al ideal de poder aportar desde dentro, desde la base, para llegar algún día a transformarla.

Periódicamente se recorre el territorio cuantas veces sea necesario, para entender la información que se ha venido tomando de forma sistemática, a fin de profundizar en esta lectura del lugar que, más allá de la mirada física y territorial, nos permitirá acceder, además, a la historia del barrio, a sus orígenes y a su proceso de consolidación (gestión urbana) a través de sus distintos actores locales, y, sobre todo, desde lo cotidiano y lo vivencial que se pueda percibir en cada recorrido, que en la medida en que lo vayamos descubriendo se irá graficando en mapas complementarios en los que dejemos evidencias de acontecimientos y hechos clave que jugaron papel fundamental en la conformación y posterior consolidación del territorio, a manera de cartografía social. En este sentido, la bitácora de apuntes gráficos y escritos nos servirá para plasmar cada uno de los hechos sociales y culturales que no percibimos desde nuestros planos urbanos y arquitectónicos para, de esta manera, poder recopilar una información que considere lo que cotidianamente sucede en estos barrios.

En esta segunda fase se adelantó un taller intensivo (workshop) en el que los estudiantes formularon propuestas rápidas de diseño a problemas específicos. En este último año se hicieron propuestas arquitectónicas para los salones comunales de los barrios Las Margaritas y Villanueva. Se tuvo una reunión preliminar en cada barrio con los representantes de la Junta de Acción Comunal, en la que se charló en torno al predio y su entorno, y a las necesidades y expectativas que se tenían, con base en lo cual se definió un programa arquitectónico por parte de los estudiantes. Una vez avanzadas las propuestas, una comisión de pobladores fue a la universidad y se les presentó el avance que se tenía, para que a partir de sus observaciones se hicieran los ajustes del caso. Finalmente, se llevaron los resultados de diseño a una asamblea más amplia de pobladores, a quienes se les hizo entrega de los resultados; la posible gestión de recursos a partir del proyecto arquitectónico que se les entregó quedó en manos de las directivas del barrio. 


\section{Expediente urbano (diagnóstico), un primer escrito sobre el problema y la oportunidad}

A partir del semestre inicial, el grupo de estudiantes se subdividió para estudiar variables relacionadas con las dimensiones urbanas, arquitectónicas, constructivas y sociales, con base en material bibliográfico, planimetría y, sobre todo, en el trabajo de campo, que les ha permitido recorrer el territorio. Además de charlar con los pobladores, y asî comenzar a compilar una invaluable información, para luego proceder a su análisis y a la elaboración de conclusiones. Este proceso riguroso y extenso se lleva buena parte del semestre y es complementado posteriormente cuando se profundice en problemáticas puntuales de proyecto, desde cada una de las distintas escalas con las que se aborda el territorio.

Con el levantamiento de información a escala de sector, barrio y vivienda, más el de la comunidad, se estructura un documento de estudio y diagnóstico (expediente urbano) a partir del cual precisamos las problemáticas y las oportunidades que encontramos en el barrio y, con base en estas, se formulan propuestas desde lo público (espacio público), lo colectivo (equipamientos) y lo habitacional (vivienda), las cuales son presentadas y consultadas a los líderes de la comunidad a través de talleres de trabajo en los que se utilizan maquetas, planos y documentos. A veces vamos al barrio, y otras veces los pobladores nos visitan en la universidad.

Posteriormente, con estudiantes y pobladores del lugar, se hacen recorridos en los que se revisa cada una de las manzanas, predio a predio, y se toma información de cada una de las viviendas, en cuanto a su nivel de consolidación y de edificabilidad, así como de los usos y estado de estas. De la misma manera, se hacen algunos levantamientos de vivienda que, acompañados de encuestas que se aplican a las familias, nos permiten conocer tanto la espacialidad de la vivienda en su interior como la caracterización de las personas que la habitan. Encontrar patrones espaciales comunes forma parte del análisis de esta variedad de viviendas, con programas arquitectónicos diversos, y con dimensiones espaciales bastante heterogéneas, los cuales se grafican y se consignan por escrito. Es lo que plantea el arquitecto López (2003, p. 111) como la ubicación de elementos de estudio o de comportamiento, claramente identificables y repetitivos, que puedan llegar a convertirse en una expresión cultural de determinado grupo, que lo diferencie de los demás escenarios de la ciudad, a manera de respuesta similar a una necesidad específica.

Este proceso de información y análisis comprende un procedimiento de graficación y escritura en profundidad que va de la mano con una serie de conclusiones que poco a poco se van estructurando desde cada una de las dimensiones estudiadas y obliga al estudiante a desarrollar de forma paralela una síntesis de diagnóstico, con base en la cual se propone y se teje en la siguiente fase la propuesta urbana y de mejoramiento barrial. Este documento queda en manos de la junta de acción comunal, que en ocasiones lo utiliza para llevar información a reuniones ante entidades municipales.

\section{Proposición global: armar el rompecabezas del mejoramiento barrial}

Esta fase se adelanta entre IX y X semestre, por cuanto aquí se desarrolla la parte propositiva a escala urbana, en el contexto del barrio y su entorno inmediato, antes de adelantar el desarrollo puntual de los proyectos arquitectónicos. Apoyándose en el estudio y diagnóstico de cada uno de los barrios, sobre todo en las conclusiones, y con base en conceptos teóricos (ecourbanismo, ecobarrio y acupuntura urbana, entre otros), se establecen lineamientos globales y criterios de intervención desde lo público, lo colectivo y lo habitacional.

Además de los recorridos por el lugar, y de las charlas y reuniones con los pobladores, los avances que se tienen en esta fase se llevan al barrio, o se hacen reuniones en el taller de trabajo en la universidad para intercambiar con los líderes comunitarios las ideas y propuestas que se empiezan a formular (Figura 11). Desde cada campo se formulan ideas-proyecto que, como piezas de un rompecabezas, nos exigen mucha coherencia en cuanto a límites y relaciones, a lo técnico y lo social, lo académico y lo popular, en el armado final de este rompecabezas que se entiende como fruto de un trabajo colectivo entre pobladores, estudiantes y profesores.

El papel que juegan la estructura ecológica principal (quebradas, vegetación y cerros, entre otras) y la estructura de movilidad (peatonal y vehicular), su estudio y proposición, como sistema que permite integrar los diversos proyectos arquitectónicos puntuales, serán piezas fundamentales que permiten estructurar la idea de mejoramiento de barrio. Asimismo, desde la caracterización de las áreas homogéneas que se pueden ubicar desde el grado de edificabilidad de las unidades de vivienda se pueden formular diversos proyectos habitacionales que combinan la vivienda nueva y el mejoramiento, la redensificación y el reasentamiento, entre otras.

\section{Diseño arquitectónico puntual. Desarrollo de las piezas del rompecabezas}

Esta fase se lleva a cabo en $X$ semestre $y$ hace referencia al proyecto puntual que cada estudiante desarrolla como trabajo de grado, el proyecto arquitectónico propiamente dicho. A partir del planteamiento general de mejoramiento barrial 


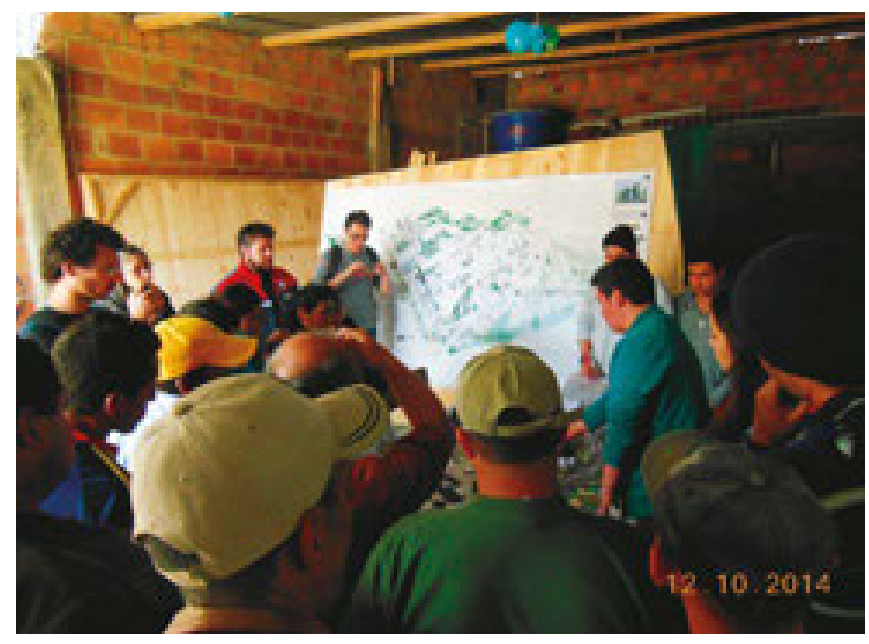

(A) Figura 11. Estudiantes exponen avances urbanos a los pobladores en el barrio

Fuente: Hernando Carvajalino Bayona, 2014
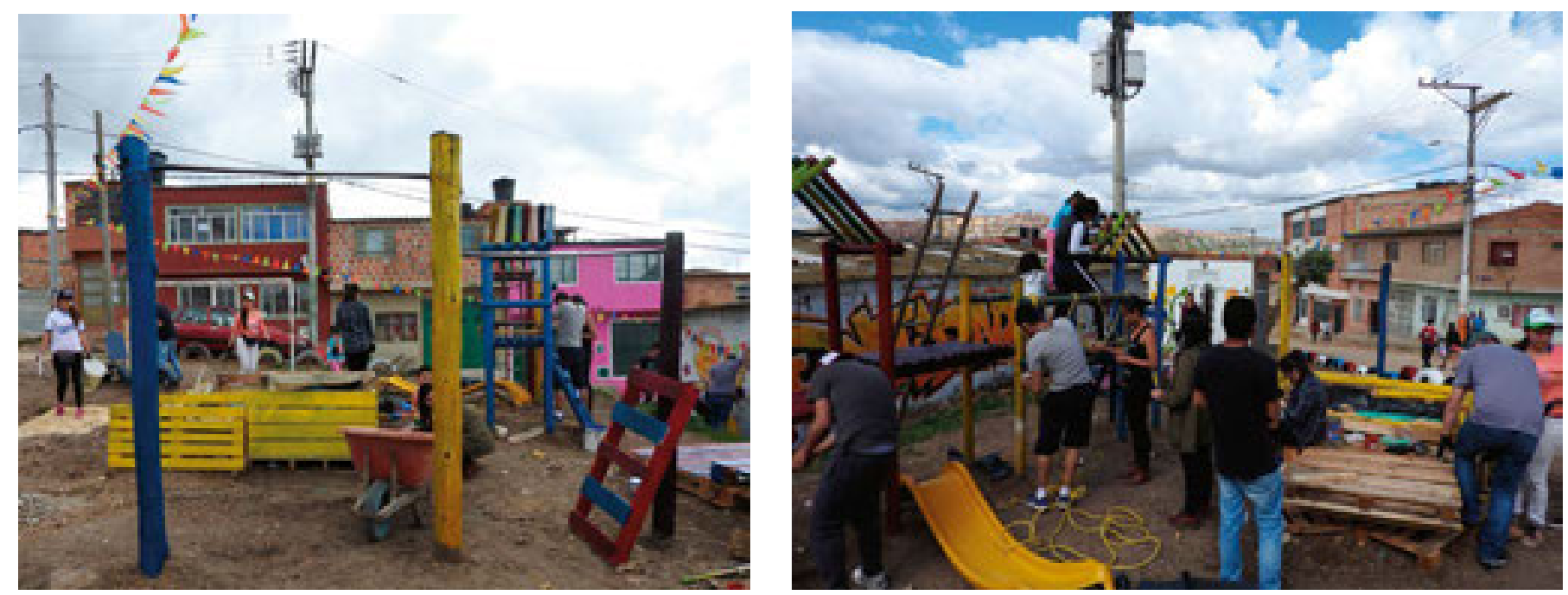

(4) (A) Figuras 13 a 16. ๑ Habilitación de ๑ un área residual en el barrio Buenos Aires Fuente: Hernando Carvajalino Bayona, 2016.
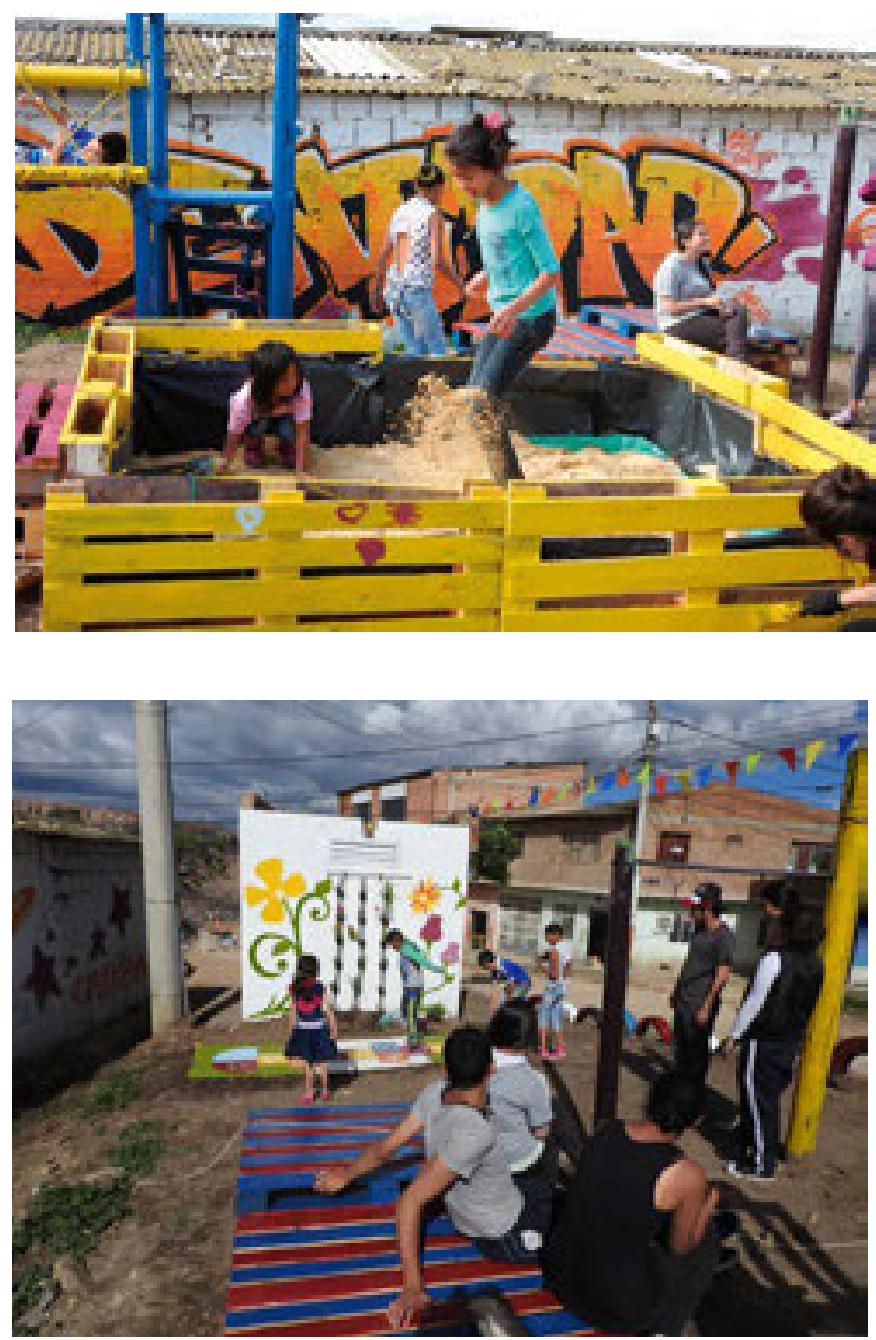

estructurado de manera colectiva en la fase anterior, y de la formulación de las ideas-proyecto individuales (criterios de diseño y demás), cada estudiante procede a la elaboración de diseños arquitectónicos específicos, desde lo público, lo colectivo y lo habitacional, involucrando en ocasiones algunos ejercicios de diseño participativo con los pobladores. Planteamientos de espacio público sobre ejes de quebradas, tratamiento de vías peatonales o el aprovechamiento de las áreas residuales, que se habilitan como parques, suelen ser algunas propuestas desde lo público. Diseños del salón comunal, la iglesia o el comedor comunitario como referente de lo colectivo, y desde lo habitacional, portafolios de diseño para lotes de $6 \times 12$, mejoramiento de vivienda o proyectos de reasentamiento, entre otros.

En este semestre, si bien cada estudiante está concentrado en su proyecto arquitectónico puntual, debe ir y venir al proyecto urbano de mejoramiento barrial para completar el tejido de espacio público que lo une con los demás proyectos. Asimismo, es necesario tener en cuenta la posible articulación que deben establecer entre sí, como sistema de equipamientos, por poner un ejemplo, y relacionarlos de forma paralela con los proyectos habitacionales de vivienda que se 

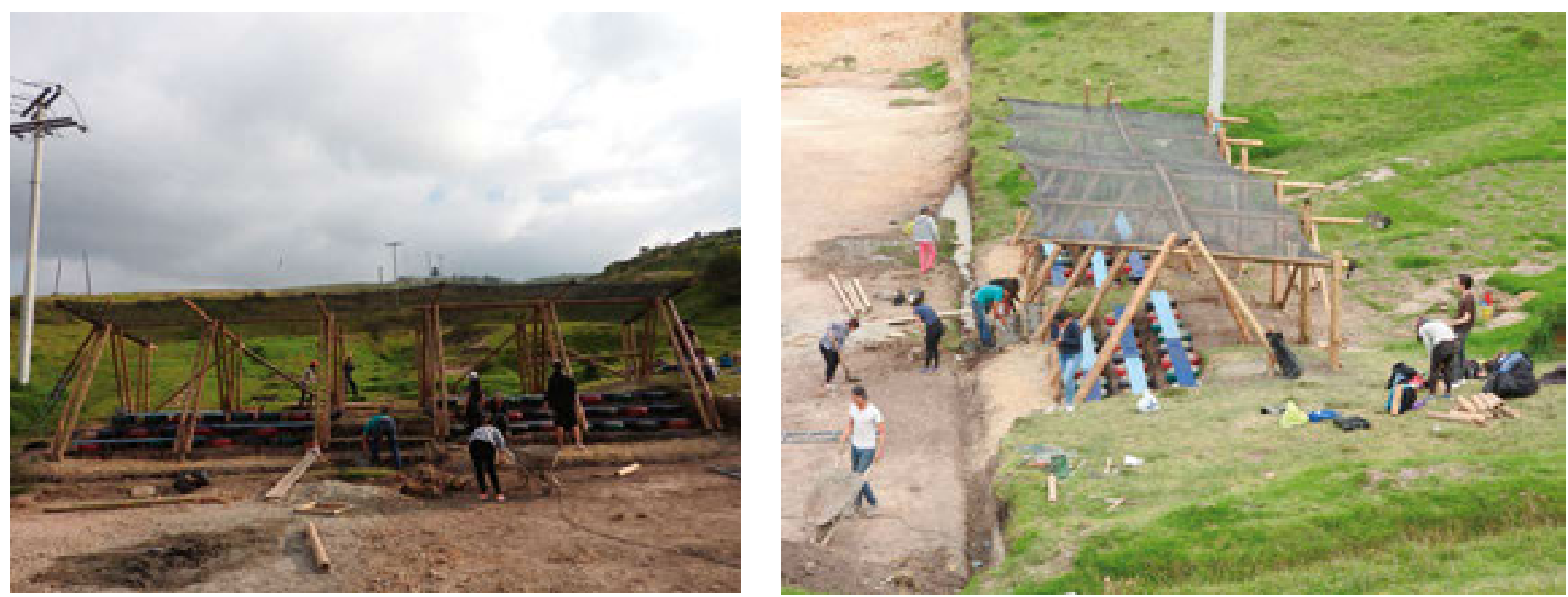

están proponiendo en cualquiera de las variables que se desarrollen (mejoramiento, vivienda nueva, redensificación o reasentamiento, entre otros), contemplando otras variables o conceptos clave en la vivienda de los barrios populares, la vivienda productiva o en arriendo. También la vivienda progresiva y flexible, por señalar algunas de las posibilidades que habitualmente se desarrollan.

En esta fase se discute previamente acerca del carácter del proyecto que, en diversas ocasiones, se mueve entre lo posible y lo real, o entre lo académico y lo exploratorio, temas que aún nos inquietan y en los que debemos profundizar en adelante. La feria de proyectos o exposición de avance de proyecto en el barrio (Figura 12), a través de asambleas generales o de recorridos por los diseños que son explicados por los estudiantes, nos han permitido que estos conversen con los pobladores y exploren reacciones frente a las propuestas que se hacen. No obstante, se tiene claro que a corto plazo debemos pasar de esta etapa de consulta a la formulación de propuestas de diseño participativo, en las que los pobladores se involucren mucho más en estos procesos de proyectación.

Finalmente, destacamos la implementación de un ejercicio práctico y real, que los estudiantes se animaron a concretar en el barrio, de la mano de cada organización comunitaria. En un primer momento (2016) se intervino en el barrio Buenos Aires, en un espacio público residual abandonado, con problemas de basuras, que mediante ejercicios rápidos de diseño y una intervención en obra de tres días, pobladores y estudiantes recuperaron para los niños del barrio, a manera de espacio de juego. Diseño, reciclaje y autoconstrucción se combinan en una corta e intensa experiencia, la cual habrá que evaluar más a fondo para determinar su continuidad y hacer los ajustes correspondientes, sobre todo al revisar la apropiación que se logre por parte de los pobladores (Figuras 13-16).
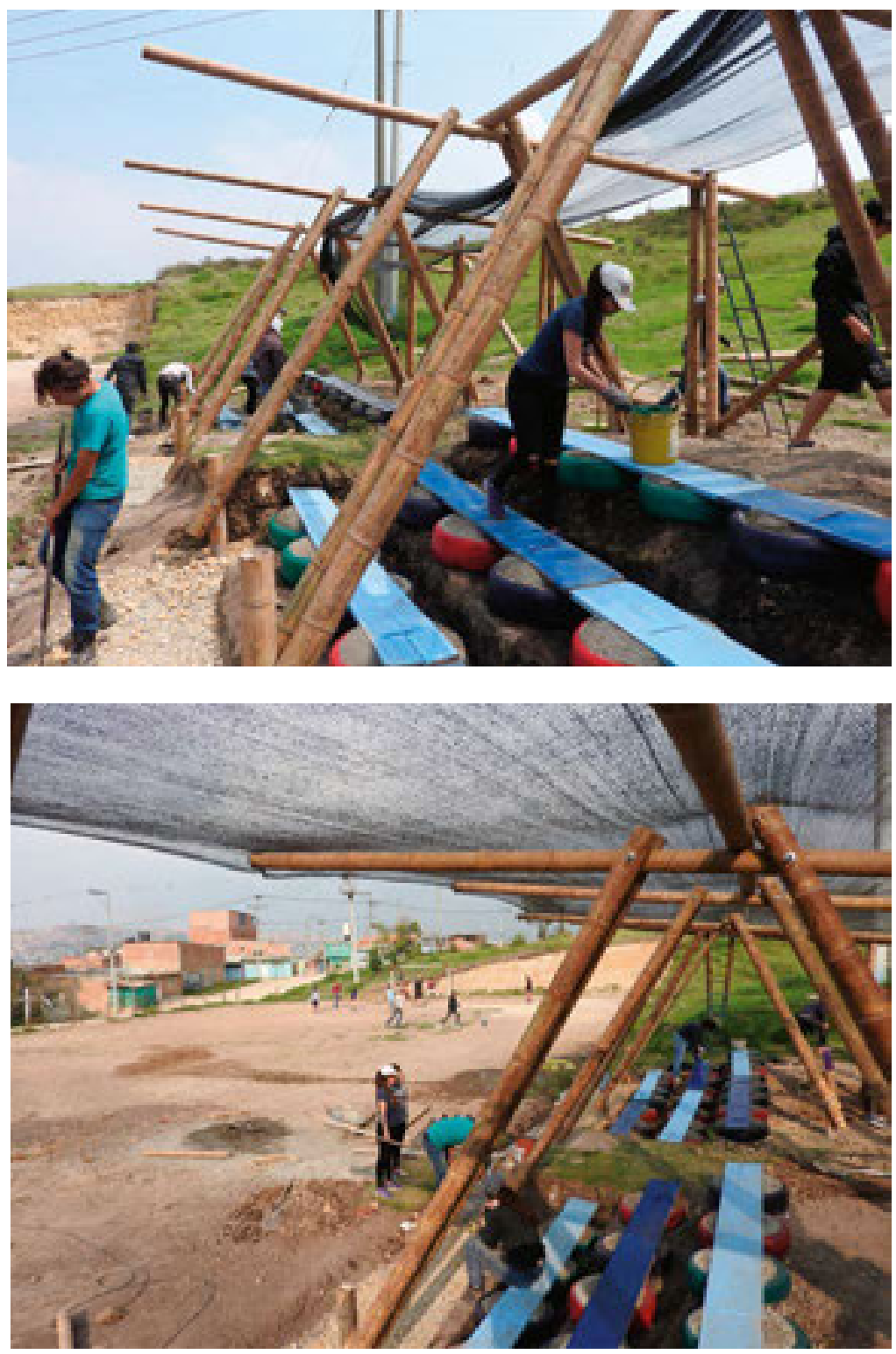

Para el 2017, en el barrio Villanueva otro grupo de estudiantes decidió hacer una intervención en la cancha del asentamiento, proponiendo un módulo de gradería, también con material reciclado (llantas y maderas), y una estructura en guadua que envolvía este sitio, desde la cual la comunidad podía sentarse a descansar o a disfrutar de los partidos. Esta labor duró nueve días y combinó un ejercicio de responsabilidad social, el diseño de la estructura y la construcción con base en un material noble, como la guadua (Figuras 17-20).
(1) (4) Figuras 17 a 20. (A) Construcción de una A gradería en la cancha del barrio Villanueva Fuente: Hernando Carvajalino Bayona, 2017. 

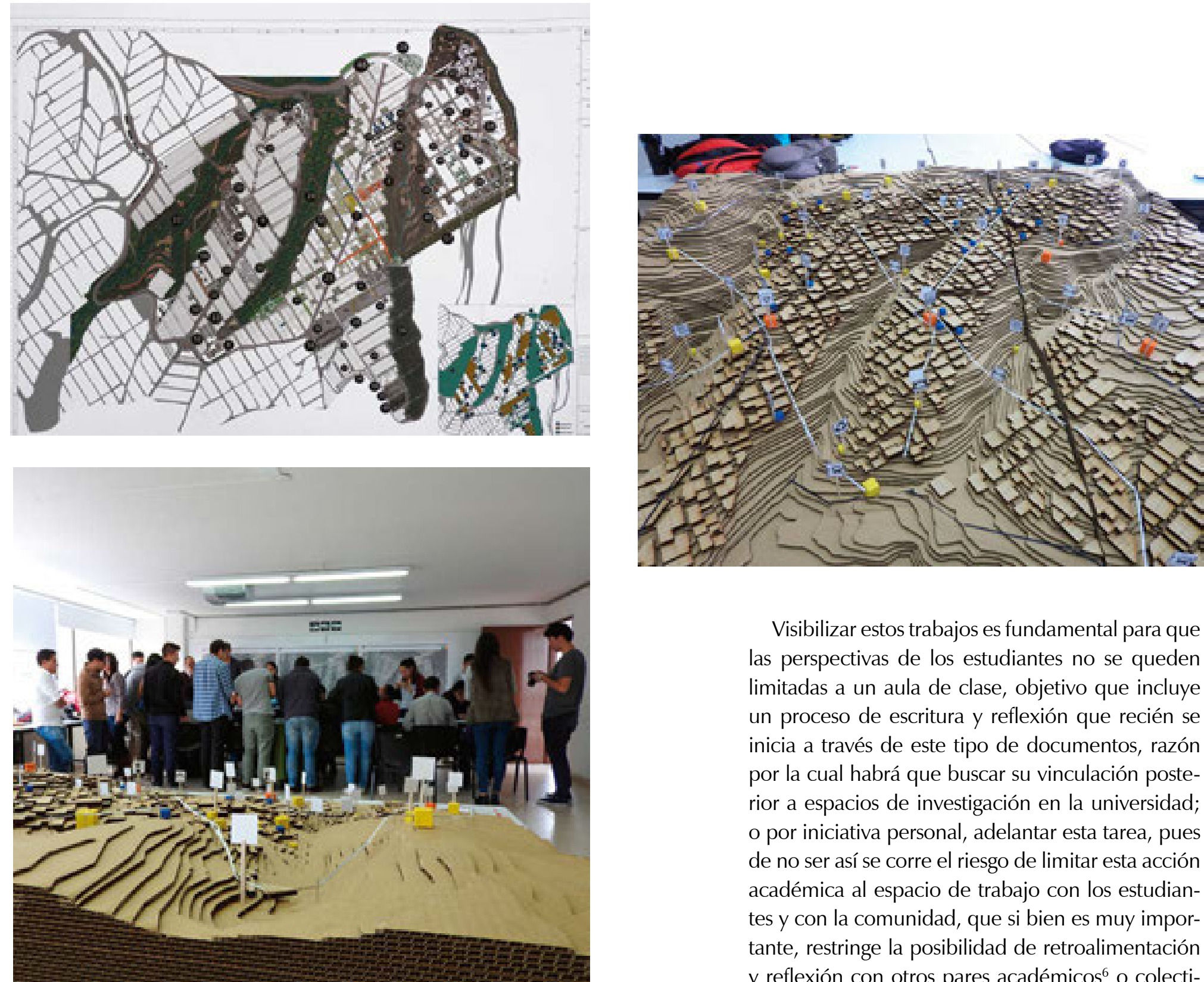

Visibilizar estos trabajos es fundamental para que las perspectivas de los estudiantes no se queden limitadas a un aula de clase, objetivo que incluye un proceso de escritura y reflexión que recién se inicia a través de este tipo de documentos, razón por la cual habrá que buscar su vinculación posterior a espacios de investigación en la universidad; o por iniciativa personal, adelantar esta tarea, pues de no ser así se corre el riesgo de limitar esta acción académica al espacio de trabajo con los estudiantes y con la comunidad, que si bien es muy importante, restringe la posibilidad de retroalimentación y reflexión con otros pares académicos ${ }^{6}$ o colectivos de trabajo barrial.

(A) (A) Figuras 21 a 23.

(A) Ejercicios proyectuales con participación comunitaria Fuente: Hernando Carvajalino Bayona, 2017
Este tipo de experiencias, para quienes participan en su formación como futuros arquitectos, tiene un significado que los sensibiliza como seres humanos frente a esta otra realidad tan compleja (Figuras 21-24).

El proceso como estudiante, el crecimiento de conocimiento hacia la arquitectura y los deberes que ello comporta crean este tipo de dedicación hacia la transformación de modos de vida, donde no se miden la estratificación, la educación o cualquier otra diferencia, sino que se pretende mejorar el hábitat donde algunas personas por conflictos, necesidad y falta de acceso a un diseño conviven en precarios lugares. En la Facultad nos dan la visión de ser, aparte de arquitectos, personas. Personas que ayudan personas. (Laiton, 2017, pp. 84-85)

\section{Discusión}

A partir de los alcances puntuales que se han logrado quedan por formular nuevas preguntas e inquietudes que nos permitan proponer otros retos para avanzar más allá del nivel alcanzado a la fecha y, desde allí, estructurar las siguientes tareas por trabajar a corto y a mediano plazo, con estudiantes de semestres posteriores.
La intervención del espacio público con proyectos puntuales reales nos dejó aprendizajes significativos; esta actividad se empezó a ejecutar desde el 2016, habilitando una zona verde residual abandonada en el barrio Buenos Aires, para convertirla en un área de juego para los niños, trabajando con material reciclado y con escasos recursos económicos; a esto se suma la que se hizo el año siguiente en el barrio Villanueva, en donde se habilitó una gradería con una estructura en guadua, con el uso de algunos materiales reciclados en la cancha del barrio. Este tipo de intervenciones tiene la gran ventaja de trascender la realidad y dejar una huella concreta en el lugar, en la misma línea de la otra discusión que se tiene en torno al alcance de los proyectos que oscilan entre lo posible y lo exploratorio. No obstante, habrá que profundizar en esquemas

6 De hecho, la participación reciente en seminarios internacionales, en la Universidad Piloto de Colombia (2015) y en la Universidad Autónoma Metropolitana de México (Azcapotzalco) (2016), ha permitido que se empiece a abrir este espacio de intercambio y retroalimentación con otras universidades y pares académicos. 
de gestión y participación que favorezcan estos procesos y garanticen su apropiación y cuidado posterior.

Terminado este sexto periodo de trabajo, los nuevos retos que quedan planteados son importantes y nos exigen, en adelante, involucrarlos en la propuesta que hasta aquí se ha presentado. A continuación se señalan algunos de los que consideramos más relevantes, veamos:

- La discusión académica entre desarrollar proyectos posibles o exploratorios se considera sana y necesaria en la medida en que es válido tener ambas posibilidades como parte de la agenda de cada semestre. Por un lado, la alternativa de avanzar en los proyectos urgentes y básicos para la comunidad, los más viables, y, por lado, la posibilidad de dejar abierto un espacio para proyectos más exploratorios que no van a tener aplicación a corto o mediano plazo, pero que nos permiten avanzar conceptualmente en torno a algunos campos sobre lo urbano y lo arquitectónico.

- En relación con los primeros será necesario avanzar en una propuesta de gestión y viabilidad de los proyectos, en la interlocución de los líderes de la comunidad con los entes municipales, para lo cual habrá que pensar en instancias de acompañamiento a este nivel. El año anterior se hizo un ejercicio con estudiantes de la maestría en Gestión Urbana de la Universidad Piloto de Colombia ${ }^{7}$, que nos permitió dar los primeros pasos a fin de ubicar posibles instituciones que puedan interesarse en estos procesos y proyectos.

- Hasta ahora nos hemos acercado al barrio y a sus pobladores, con quienes hemos conversado y trabajado a nivel de talleres para aproximarnos a sus necesidades y expectativas, a su forma de vida. No obstante, han sido instancias más consultivas que participativas. Avanzar en la implementación de procesos de diseño participativo es otro de los retos por afrontar en adelante.

- Queda abierta como posibilidad futura que la universidad, la cual cuenta con otras disciplinas (Ingeniería, Psicología y Derecho, entre otras), posibilite para el caso de Ciudadela Sucre, el vínculo con estas otras áreas del conocimiento, que permitan una mirada mucho más integral; queda pendiente hacer la gestión del caso, una vez se definan nuevas líneas de intervención.

- Queda, además, el reto de avanzar con la idea de continuar con la sistematización de la expe-

7 Este trabajo académico se realizó en el año 2017, en la asignatura Redes y Gestión Democrática de la Ciudad, Maestría de Gestión Urbana de la Universidad Piloto de Colombia, en Bogotá.

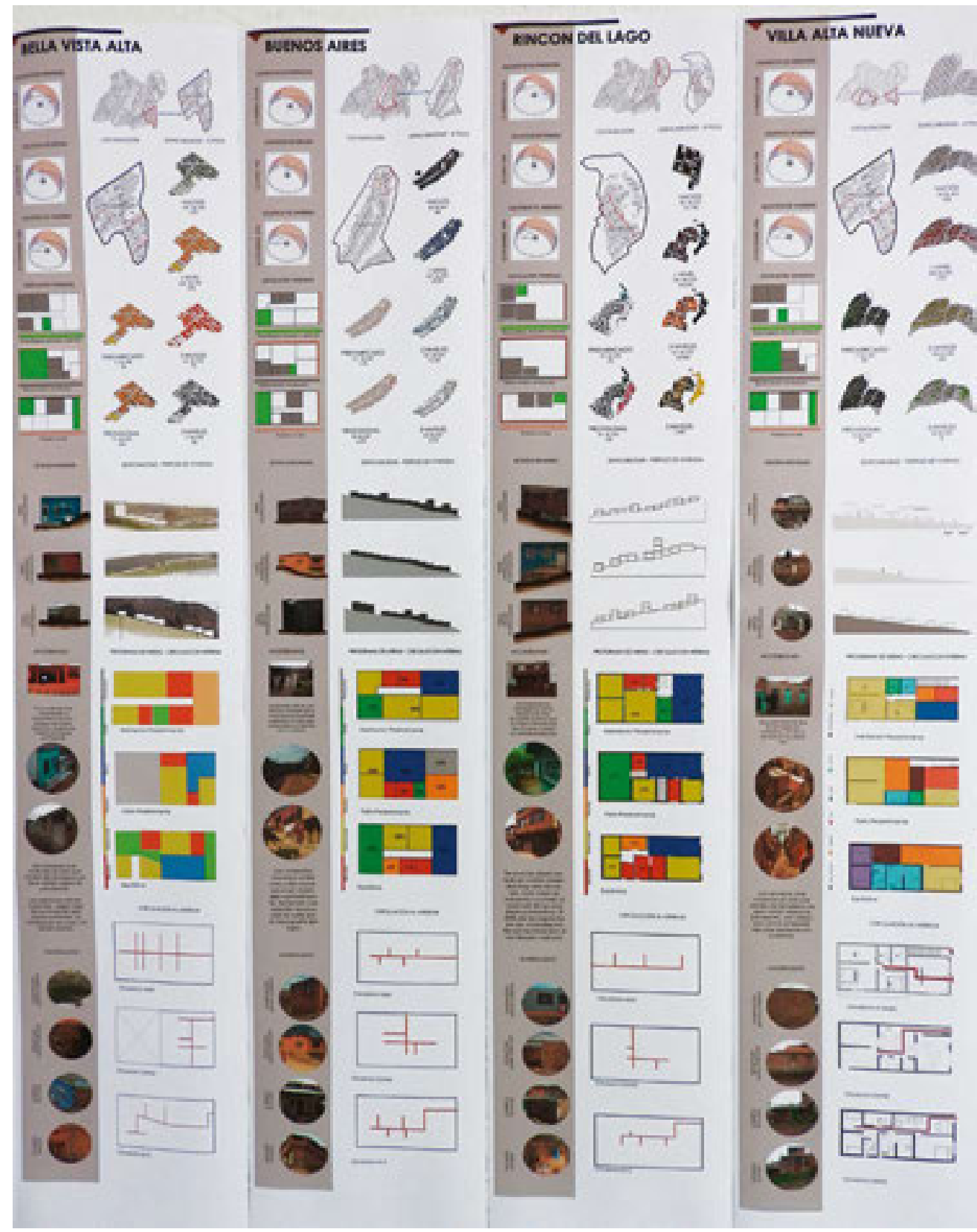

riencia y en su proceso de escritura ${ }^{8}$. Si bien este proyecto académico no forma parte de un espacio de investigación en la universidad, se tendrían que seguir haciendo esfuerzos paralelos, muy personales desde cada profesor, para elaborar textos como este, que apunten a fortalecer la divulgación de la experiencia.

\section{Conclusiones}

La ganancia que se ha obtenido y que es un componente innovador al interior de cualquier facultad de Arquitectura desde la perspectiva de nuestro contexto local, es haber llevado la academia al barrio popular, haberla instalado allí de forma periódica y constante en los extramuros, anclada durante varios años de manera ininterrumpida (Figura 25). Así, se ha logrado estructurar como un espacio de estudio, reflexión y

8 El presente artículo se elaboró con base en una ponencia que se llevó al Seminario Internacional: "Aprendizajes Comunes desde los talleres de diseño arquitectónico: miradas latinoamericanas", convocado por la Universidad Autónoma Metropolitana de México (Azcapotzalco), en el que participaron arquitectos de Argentina, Colombia, México y Uruguay, en el mes de diciembre de 2016.
(A) Figura 24. Ejercicios proyectuales con participación comunitaria Fuente: Hernando Carvajalino Bayona, 2017 
explorando. Recientemente se pudo evidenciar que los primeros resultados se empiezan a dar, pues Hábitat para la Humanidad realizó varios mejoramientos de vivienda con base en trabajos adelantados por los estudiantes, y con recursos que esta ONG consigue en otros países. Además, el cerramiento para el colegio del barrio Rincón del Lago se pudo concretar a partir de uno de los proyectos académicos realizados, dado que la Junta de Acción Comunal consiguió recursos para su cerramiento a partir de estos proyectos. No obstante, hay que seguir profundizando en nuevos esquemas de gestión que permitan ampliar una perspectiva más real y concreta en favor de la comunidad.

Dada la coyuntura política de nuestro país, estamos en un momento histórico en el que Colombia está encaminada hacia un proceso de paz definitivo con las fuerzas insurgentes. De concretarse, se viene enseguida la hora de enfrentar a fondo el conflicto social que aqueja a una sociedad inequitativa como la nuestra, momento que seguramente va a posibilitar que estas experiencias con sectores populares, tanto en escenarios rurales como urbanos, se sigan cualificando y se multipliquen, tanto desde el ejercicio académico como desde la vida profesional de nuestros futuros arquitectos. Haber posibilitado estas experiencias académicas a manera de camino por recorrer es un logro en cuanto a lo que se ha avanzado y todo un reto que se nos propone en adelante, con una serie de tareas por emprender en torno a un nuevo país que necesita compro- meterse de manera inmediata y a corto plazo en el mejoramiento de las condiciones de vida de la población económicamente menos favorecida, a partir de los acuerdos de paz.

\section{Agradecimientos}

Agradecimiento profundo a los integrantes de las juntas de acción comunal de los barrios en los que hemos trabajado, lo mismo que a sus líderes y pobladores, que nos han abierto las puertas del barrio y de sus casas. Es hacia ellos que enfocamos este proceso académico y comunitario.

Esta experiencia no hubiese sido posible sin el aporte académico de un grupo amplio de estudiantes y profesores que han acompañado este proceso, en diversos periodos de estos últimos seis años.

Al día de hoy forman parte del equipo la arquitecta Natalia Medina (diseño urbano) y el ingeniero José Antonio Magallón (diseño constructivo). En años anteriores han participado en diseño urbano, el arquitecto Javier Sarmiento, y en diseño constructivo, los arquitectos Rolando Cubillos, Lucas Pardo y Víctor Arcos.

Una especial mención y agradecimiento al señor decano, arquitecto Werner Gómez; al director de docencia, arquitecto Jorge Gutiérrez, y al jefe de Núcleo, arquitecto Orlando Martínez, quienes han brindado un apoyo pleno, más la confianza y la autonomía del caso, para que este tipo de experiencias puedan funcionar de manera abierta a los cambios que se vayan presentando en su desarrollo.

\section{Referencias}

Avendaño, F. y Carvajalino, H. (2003). Vivienda popular espontánea: conceptos de espacialidad y progresividad. Reflexiones a partir de un estudio de caso: Bogotá, Colombia. Revista Ciudad y territorio, estudios territoriales, XXXV(136-137), 391-420. Recuperado de https://dialnet.unirioja.es/ servlet/articulo?codigo $=819548$

Borja, J. y Castell, M. (1999). Local y global. Madrid: Taurus.

Carvajalino Bayona, H. (2009). Hábitat popular y programas de mejoramiento: intervenir escenarios en proceso de consolidación. Revista INVI, 2O(53), 108-133. Recuperado de http://revistainvi.uchile.cl/index.php/ INVI/article/view/336/880

Carvajalino Bayona, H. (2013). Aprendiendo del Barrio la Paz: un escenario desde el cual vincular la academia a esta otra arquitectu- ra. Revista de Arquitectura (Bogotá), 15(1), 120-130. Doi: http://dx.doi.org/10.14718/ RevArq.2013.15.1.13

Carvajalino Bayona, H. (2016). Arquitectura de lo in-visible (...o de lo que no queremos ver). Nodo, 10(20). Recuperado de http:// revistas.uan.edu.co/index.php/nodo/issue/ view/58

Carvajalino Bayona, H. (2019). Barrios populares: alternativa a la crisis habitacional, desde los pobladores. Credencial Historia (Arquitectura en Colombia), 349, 12-15 Recuperado de http://www.revistacredencial.com/ credencial/historia/temas/barrios-populares-alternativa-la-crisis-habitacional-desde-los-pobladores

Facultad de Arquitectura (2010). PEP arquitectura. Proyecto educativo del programa (3 ed.). Bogotá: Universidad Católi- ca de Colombia. Recuperado de https:// www.ucatolica.edu.co/portal/wp-content/ uploads/adjuntos/programas/arquitectura/ pep-arquitectura.pdf

Laiton-Suárez, M. (2017). Prototipos flexibles. Proyecto habitacional en el barrio popular Buenos Aires (Soacha). Revista de Arquitectura (Bogotá), 19(1), 70-85. Doi: http://dx. doi.org/10.14718/RevArq.2017.19.1.1271

López, W. (2003). Origen de la informalidad urbana en Bogotá, años cincuenta. Bogotá, D. C.: Universidad Piloto de Colombia.

Sociedad Colombiana de Arquitectos (SCA) (2015). 15 anual de estudiantes de arquitectura. Replanteo, 15, 1-85. Recuperado de http://scabogota.org/wp-content/ uploads/2018/07/REVISTA-REPLANTEO-16. pdf 



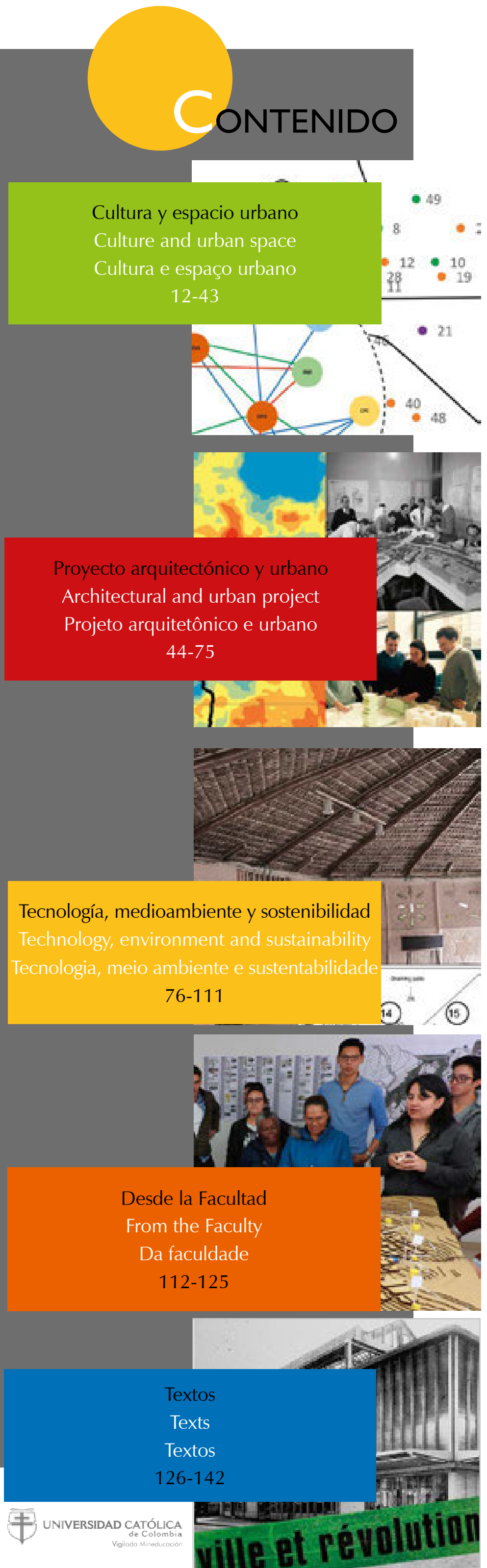

Arquitecturas colectivas y participación como estrategias para la construcción de la ciudad latinoamericana

Myriam Stella Díaz-Osorio

Pág. 3

ES

La caminabilidad en Bogotá: propósitos y condiciones socioespaciales que facilitan y limitan esta experiencia Pablo Páramo

Andrea Burbano

Pág. 12

ES EN

Planificación comunitaria en barrios socialmente

vulnerables. Identificación de los actores sociales en una comunidad

Rafael Alejandro Tavares-Martínez

Jesús Manuel Fitch-Osuna

Pág. 22

ES

Desvanecimiento de la frontera como límite. Imaginario del borde como espacio público físico y virtual

Gabriela Eloísa Muñoz-Torres

Susana Gutiérrez-Luna

Pág. 33

Estudiantes latinoamericanos en el Institut

d'Urbanisme de l'Université de Paris (1923-1941)

$$
\text { Andrés Ávila-Gómez Pág. } 44
$$

ES

Apuntes para el repensamiento de la enseñanza de la Arquitectura. La cuestión epistemológica y la necesidad de una razón ampliada
Juan J. Álvarez-Álvarez
Pág. 57

ES

Equipamientos colectivos: "lugares" de producción de capital social
José Mario Mayorga-Henao
Pág. 68
ES
Bucle multidisciplinar para la sustentabilidad urbana
Luis Fernando Molina-Prieto
Mónica Suárez-Serrano
María Eugenia Villa-Camacho
ES EN
Pág. 76

Durabilidad de los materiales naturales de construcción:

percepciones de proyectistas, constructores y usuarios en Florianópolis, Brasil

Andrea Salomé Jaramillo-Benavides
Zuleica Maria Patricio-Karnopp
Lisiane Ilha-Librelotto

Pág. 89

ES

Thermal comfort in buildings for wet processing of coffee

Lina Marcela Guerra-García

Ilda de Fátima Ferreira-Tinôco

Jairo Alexander Osorio-Saraz

Robinson Osorio-Hernández

Pág. 101

EN

La arquitectura en los barrios: puntos de encuentro entre la academia y el saber popular

Hernando Carvajalino-Bayona

Pág. 112 ES

Arquitectura, modernidad, modernización

$$
\begin{aligned}
& \text { Jean-Louis Cohen } \\
& \text { Traductores } \\
& \text { Andrés Avila-Gómez } \\
& \text { Diana Carolina Ruiz } \\
& \text { ES }
\end{aligned}
$$


Arquitecturas colectivas y participación como estrategias para la

Arquiteturas coletivas e participação como estratégias para construir a cidad latino-americana

\section{yriam Stella Díaz-Osorio}

La caminabilidad en Bogotá: propósitos y condiciones socioespaciales que facilitan y limitan esta experiencia

The Walkability of Bogotá: purposes and socio-spatial conditions that facilitate and limit this experience

A caminhabilidade em Bogotá: propósitos e condições socioespaciais que facilitam e limitam essa experiência

\section{Andrea Burbano}

Planificación comunitaria en barrios socialmente vulnerables.

Identificación de los actores sociales en una comunidad

Community planning in socially vulnerable neighborhoods.

Identification of social actors in a community

Planejamento comunitário em bairros socialmente vulneráveis.

Identificação dos atores sociais em uma comunidade

Rafael Alejandro Tavares-Martinez

esús Manuel Fitch-Osuna

Desvanecimiento de la frontera como límite. Imaginario del borde como espacio público físico y virtual

$m$

迹 Durabilidad de los materiales naturales de construcción: percepcione
de proyectistas, constructores y usuarios en Florianópolis, Brasil

Durability of natural building materials: Perceptions of designers, builders, and users in Florianópolis, Brazil

Durabilidade dos materiais naturais de construção: percepções de projetistas, construtores e usuários em Florianópolis, Brasil

\section{Andrea Salomé Jaramillo-Benavides}

isiane Illha-Librelotto

Thermal comfort in buildings for wet processing of coffee

\section{Confort térmico en edificaciones para procesamiento húmedo de café}

这

\section{Conforto térmico em instalações para processamento úmido de café \\ ina Marcela Guerm-Garcia \\ Ilda de Fátima Ferreira-Tinôco}

Jairo Alexander Osorio-Saraz

\section{Robinson Osorio-Hernandez}

La arquitectura en los barrios: puntos de encuentro entre la academia y el saber popular

Architecture in neighborhoods: meeting points between academia and popular knowledge

A arquitetura nos bairros: pontos de encontro entre a academia e o saber popular Hernando Carvajalino-Bayona

\section{Arquitectura, modernidad, modernización}

Architecture, modernity, modernization

Arquitetura, modernidade, modernização
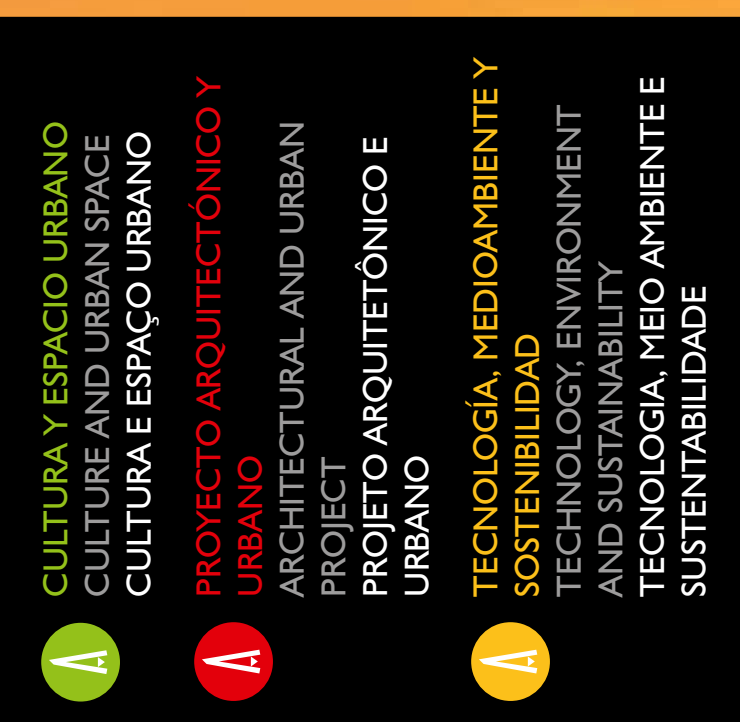

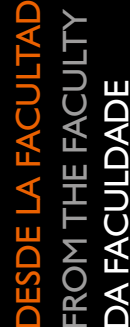

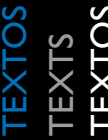
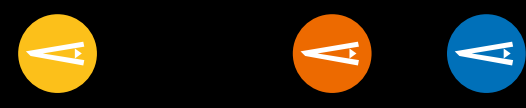

D clarivate

Clarwate

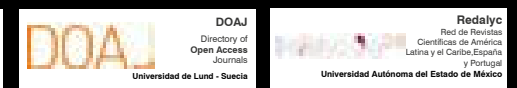

1

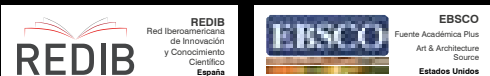

d

leing

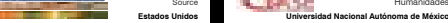

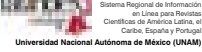

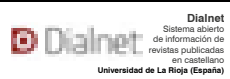

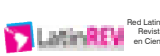

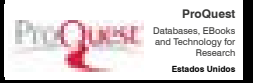

MIคR

8.

Google

ARLA

82. https://www.mendeley.com/profles/revista-de-arquitectura-bogot/ 